\title{
Prevalence of Intestinal Parasitic Infection among Food Handlers in Northwest Iran
}

\author{
Davoud Balarak, ${ }^{1}$ Mohammad Jafari Modrek, ${ }^{2}$ Edris Bazrafshan, ${ }^{1}$ \\ Hossein Ansari, ${ }^{3}$ and Ferdos Kord Mostafapour ${ }^{1}$ \\ ${ }^{1}$ Department of Environmental Health, Health Promotion Research Center, Zahedan University of Medical Sciences, Zahedan, Iran \\ ${ }^{2}$ Department of Parasitology, Infectious Diseases and Tropical Medicine Research Center, \\ Zahedan University of Medical Sciences, Zahedan, Iran \\ ${ }^{3}$ Department of Epidemiology and Biostatistics, Health Promotion Research Center, Zahedan University of Medical Sciences, \\ Zahedan, Iran
}

Correspondence should be addressed to Davoud Balarak; dbalarak2@gmail.com

Received 30 October 2015; Revised 22 January 2016; Accepted 22 February 2016

Academic Editor: Dong H. Shin

Copyright (c) 2016 Davoud Balarak et al. This is an open access article distributed under the Creative Commons Attribution License, which permits unrestricted use, distribution, and reproduction in any medium, provided the original work is properly cited.

\begin{abstract}
Parasitic diseases are among the most important infectious diseases and pose health problems in many countries, most especially in developing countries. Workers at food centers could transmit parasitic infections in the absence of sanitation. This is a descriptive study conducted to determine the prevalence of intestinal parasitic infections in food clerks in the city of Tabriz in 2014. Data was recorded in the offices of the health center for all food handlers who were referred to the laboratory for demographic and stool tests to receive the health card. Parasitic infection was observed in 172 cases (3.73\%) of 4612 samples. A total of 156 positive samples $(90.69 \%)$ were related to protozoa and 16 (9.3\%) were related to helminthes. Most of the parasitic infections were related to Giardia and Entamoeba coli and the lowest infection was related to H. nana. Also, there was a significant relationship between level of education and parasitic infection rate $(P=0.0044)$. But there was no significant difference between the type of infection and amount of intestinal parasites. The results show that the prevalence of intestinal parasites, especially pathogenic protozoa, is common in some food handlers. Therefore, more sanitary controls are required and increasing of education will play a crucial role in improving the health of these people.
\end{abstract}

\section{Introduction}

The parasitic infections are considered as one of the major health problems in the world and especially in developing countries [1,2]. According to the World Health Organization (WHO), nearly two-thirds of the world is infected with one kind of intestinal parasite and Ascaris and Giardia infections have the highest rate among all kinds [3]. Due to geographical location, climate, extent of the area, and cultural and biological characteristics, there is a suitable environment for the activity of various parasites in Iran $[4,5]$. The reasons for high incidence of parasites in some parts of the country are a result of specific climate of the regions, local customs, and the use of human and animal fertilizers in agriculture and olericulture [6]. Lack of clean and safe water, high population density, lack of proper disposal of waste, noncompliance with health standards (social and individual), lack of adequate washing of vegetables, and lack of well cooked meat lead to high prevalence of intestinal parasites $[7,8]$. Studies in different parts of Iran revealed that there is infection of intestinal parasites between studied groups. For this reason, several studies have been conducted on the prevalence of parasitic infections in different parts of the country that show the prevalence of parasitic infections between 2 and $61 \%$ in studied populations [9-11]. According to pervious researches, the prevalence level of parasitic diseases was as follows: Kermanshah (59.13\%) [3], Mazandaran (21\%) [12], Kashan (46.9\%) [13], and Ardabil (27.7\%) [14], while it was 13.7\% and 8.4\% for Semnan [15] and Ghaemshahr [16] that indicates the great prevalence of these infections from the statistical viewpoint. As a result of the high incidence of parasitic infection in the country, the identification of infection, knowing the 
methods of transmission, and preventing their transmission are of paramount importance and are considered as health priorities [17].

One of the most important areas of risk of intestinal parasitic infections in the community is the risky nature of some jobs. These conditions facilitate the transmission of disease through the close contact with the infectious sources that are an integral part of some of the jobs, so they provide the possibility of easy infection [18]. The production and sales of health food products are always a concern in many developed and developing countries. Today, a number of factors including existence of quality control procedures, strict supervision of production processes, reduction in the amount of contact with food, and food categories in the process of production are the most important tasks in the production of high quality products. In this case, the role of food handlers, as the final agent of product provider, is very important because they can make unsafe and hazardous foods for consumption. If these people fail to follow the principles of primary health care and personal hygiene, they are considered as one of the main sources of transmission of pathogens through food and can easily pass many infectious agents, especially intestinal parasites to their customers $[18,19]$. Obviously, the study of parasitic diseases among employees of the food industry and the prevalence rate of infection in them will help to reduce and control the spread of these diseases. Since our country has several areas with different climatic diversity and social and cultural patterns, study of parasitic infections in any province or region is absolutely necessary.

Given the role of food handlers in the spread of parasitic diseases and also due to the prevalence of infection in the country and lack of awareness towards the infection level in the city of Tabriz, this study was conducted to investigate the intestinal parasitic contamination in food handlers in the city of Tabriz in 2014.

\section{Materials and Methods}

According to existing regulations, Health Care Card is necessary to monitor the health status of employees in the health sector of different jobs and especially jobs that were related to food. All those who were responsible for procurement, distribution, and sale at food centers have referred to health centers to extend their Health Care Cards twice per year. The food handlers should undergo the necessary tests, especially parasitic tests, to receive the Health Care Card. For each food handler, 3 stools were tested by direct method (wet method with Gram) and the results were recorded along with other personal information such as age, sex, and address in the offices for each job. According to the Office Inspection Act of Tabriz, everyone is required to obtain a Health Care Card and undergo test for parasites. In this study, the recorded data related to epidemiological intestinal parasitic infection of individuals who are working at procurement, distribution, and sale of food products in public places of Tabriz in 2014 were used. In addition, other data including details of the type of business, business location, gender, and the results of tests were obtained from these offices. Based on the present data, Tabriz city had 1465 center for sales and distribution of food in
2014 and a total of 4612 person were working at these centers. The results of tests were analyzed by Spss version 18 (IBM, USA) using the chi-square test and t-test.

\section{Result}

The results showed that 3966 male food handlers (85.99\%) and 646 female food handlers (14.01\%), who were engaged in the distribution and sale of food, have been referred to health centers to achieve the Health Care Card. Their ages were between 14 and 68 years. The education level of the food handler was observed to be under high school diploma (30.68\%), high school diploma to B.S. (58.2\%), and over B.S. (11.12\%). Table 1 shows the number of positive cases according to age, sex, and education level. There was no significant difference between age and gender in any case. The infection was observed in 156 cases (3.38\%) of males and 16 cases $(0.345 \%)$ of females but statistically significant difference was not observed in this field $(P=0.094)$.

Parasitic comparison between the food suppliers is given in Table 2, indicating that the highest percentage of infection is related to restaurants and supermarkets, but in general, there was no statistically significant difference between different professions $(P=0.112)$. A total of 172 subjects $(3.73 \%)$ were diagnosed with intestinal parasites and five types of intestinal parasites; Giardia lamblia, Entamoeba coli, Ascaris, Entamoeba histolytica, and $H$. nana were observed. Most of the infections were related to Giardia with 109 (63.33\%) of 172 positive cases. Entamoeba coli infection was recorded as 38 positive cases (22.1\%), while Ascaris infection was 10 cases $(5.83 \%)$. Furthermore, the parasitic worm infection was related to Ascaris and $H$. nana and equal to 16 cases (0.38\%) but protozoa infections were 156 cases (3.38\%).

\section{Discussion}

The result of this study showed that $3.73 \%$ of the food handlers in Tabriz were infected with intestinal parasites. The parasitic infections in this study were less than the results of other studies which have been conducted in Yazd [10], Varamin and Sanandaj [20, 21], and Hamadan [22]. These studies have been conducted in the past decade and, as it was stated, show high amounts of parasitic infection, but in the present decade their prevalence in different areas has significantly declined parallel to improvement of public health. One of the most effective methods in reducing parasitic infection was strict enforcement of sanitary regulations in recent years, so that all people in Tabriz were issued a Health Care Card and parasitological tests were performed on them accurately.

The highest prevalence of infection was in supermarket and sandwich and pizza businesses which recorded 22.1, 8 and $19.2 \%$ of parasitic infections, respectively. The case study conducted in Kerman by Salary and Safizadeh is fully in accordance with the results of our study, so that the maximum amount of infection was $27.1 \%$ which was recorded for supermarket workers and clerks among the food handlers of Kerman [11]. Also, the prevalence level was reported to be $30.2 \%$ in another survey that was conducted by Rouhani et al. in Nowshahr and Chaloos on various food vendors 
TABLE 1: The number of positive cases of parasites in food production and distribution centers employees in the city of Tabriz according to individual characteristics.

\begin{tabular}{|c|c|c|c|c|}
\hline \multirow{2}{*}{ Characteristics } & \multicolumn{2}{|c|}{ Studied people } & \multicolumn{2}{|c|}{ Positive cases } \\
\hline & Numbers & $\%$ & Numbers & $\%$ \\
\hline \multicolumn{5}{|l|}{ Gender } \\
\hline Male & 3966 & 85.99 & 156 & 3.38 \\
\hline Female & 646 & 14.01 & 16 & 0.345 \\
\hline \multicolumn{5}{|l|}{ Age (year) } \\
\hline Under 20 & 418 & 9.05 & 20 & 0.433 \\
\hline 20 to 40 & 2576 & 55.85 & 108 & 2.34 \\
\hline Over 40 & 1618 & 35.1 & 44 & 0.954 \\
\hline \multicolumn{5}{|l|}{ Education } \\
\hline Under high school diploma & 1415 & 30.68 & 68 & 1.75 \\
\hline High school diploma to B.S. & 2684 & 58.2 & 76 & 1.64 \\
\hline Over B.S. & 513 & 11.12 & 28 & 0.607 \\
\hline
\end{tabular}

[23]. Koohsar et al. have also reported that intestinal parasitic infection in food handlers of Gorgan was equal to $6 \%$. According to these observations, most parasitic infections were caused by butchery staffs by $25 \%$ and the highest rate of infection was due to the parasite Giardia [24]. The difference between the results could be due to the sample size, the studied population, social, economic, and geographical characteristics, and climate changes, including humidity and heat, direct exposure to the sun's rays, and a lack of vegetation. In another study, the reason for these differences is highlighted [25]. Kamau et al. have conducted a similar study in Kenya and they found out that Giardia parasite is one of 6 common types of parasites among members of restaurant staff [26].

Although there is no direct contact with food by supermarket worker as other businesses but the contamination of food are possible when they are uncovered; therefore, sandwich, pizza, and restaurant handlers have most contribution in incidence of parasitic infection after supermarkets, which is accordance with most studies in the our country. Since these groups have direct contact with food, intestinal parasitic infection is more possible; thus the staff in these sites require personal and professional hygiene in their work environment, and these health professionals are decisively required to follow up and monitor. In this study, most parasitic infections are related to Giardia with 109 of the 172 positive samples which assigned $63.37 \%$ of the total parasitic infection that are well correlated to the study that took place in the city of Kerman by Salary and Safizadeh but the Giardia parasite has been isolated only in their study which is considered as difference with our study [11]. In another study, the prevalence of intestinal parasites was recorded in food handlers involved in the procurement, distribution, and sale of food in public places in Gilan Province and it was detected that the most common parasite is Giardia [9]. The studies conducted in Saudi Arabia and Sudan cleared that Giardia and E. histolytica parasites were observed in food handlers and the amount of Giardia parasite was very high in Sudan [27, 28].

In this study, the rate of infection with worms was 16 samples $(0.345 \%)$ and protozoan infection was at the rate of 156 samples (3.38\%). These findings are in line with the earlier studies conducted by Kheyrandish et al. in Khorramabad, Shidfar et al. in Ilam, and Balarak et al. in Ahar [29-31]. Also, a correlation was found with a study in Ethiopia and India $[32,33]$. These studies show higher prevalence of protozoan parasites than worms. The high prevalence of protozoan parasites is due to the proliferation of the spread and ability to produce large simple cysts and protozoa stability in environmental conditions [34]. In the study conducted in Nigeria and Manila, protozoan parasites like Giardia and Entamoeba coli were more observed, due to the higher proliferation of protozoa than worms $[35,36]$. According to various studies, it is indicated that the prevalence of intestinal parasitic infections has recently changed compared to the past and the prevalence of infection has declined, totally. The reduction in the incidence of infections over the years can be attributed to the development of networks for the distribution of drinking water, more comprehensive monitoring of health systems, and ongoing communication with employees and stricter rules than in the past to provide health advice and provide hygiene standards, continuous testing of parasitic infections (6 months) and the availability of drugs for the treatment of infections, higher levels of life expectancy in terms of health and increasing level of individual health information and the use of less human fertilizer by farmers $[19,37]$.

Literacy level reduces the number of positive samples; in other words, there is a significant relationship between level of education and degree of parasitic infection $(P=$ 0.0044 ). It could be interpreted that if the literacy rate increased, then awareness about parasitic infections will also increase. Therefore, the lower need for health advice and better compliance with sanitary regulations will be achieved, as noted in other studies [29]. People in South-East Asia have less knowledge about these infections; thus, there are more infections in those regions [38], while the infection level is less in developed countries like Italy [39].

\section{Conclusion}

The results show that the prevalence rate of intestinal parasites, particularly Giardia protozoan, in food handlers is 


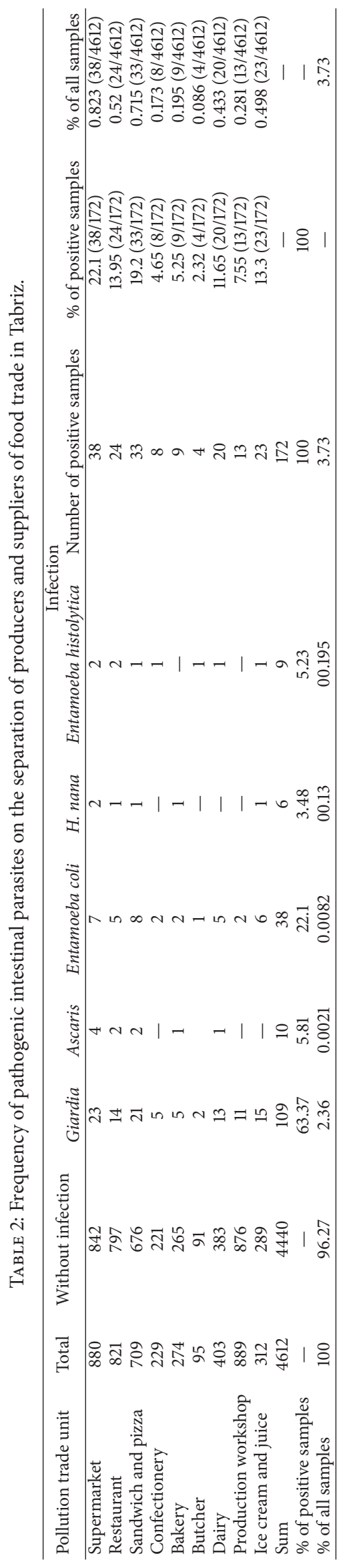


$3.73 \%$. This percentage of infection between the workers in food producing places can be considered as an important way to transmit and incidence of these infectious agents among the public. Therefore, the attention to the health status of these places and the continuous monitoring of the workers in these places can play significant role to prevent the infection. Furthermore, holding of training and educational programs leads to increase the knowledge of the workers towards these infections and the associated risk to themselves and their community which can be assumed as other effective factors to diminish the health risk problems associated with this sector.

\section{Competing Interests}

The authors declare that they have no competing interests.

\section{References}

[1] M. Malakotian, M. Hosseini, and H. Bahrami, "Survey of the parasires of vegetable in Kerman province," Medical Journal of Hormozgan University, vol. 13, no. 1, pp. 55-62, 2009.

[2] M. Shahnazi, M. Sharifi, Z. Kalantari, M. Alipour Heidari, and N. Agamirkarimi, "The study of consumed vegetable parasitic infections in Qazvin," The Journal of Qazvin University of Medical Sciences, vol. 12, no. 4, pp. 83-89, 2009.

[3] M. Vojdaani, A. Barzegar, and A. Shamsiaan, "Frequency of parasitic infections in patients referred to special clinic of Kermanshah University of Medical Sciences in years 1995-99," Journal of Kermanshah University of Medical Sciences, vol. 6, no. 2, pp. 31-37, 2002.

[4] T. K. Hazrati, M. Mostaghim, H. Khalkhalli, and M. A. Aghayar, "The prevalence of intestinal parasitic infection inthe students of primary schools in Nazloo region in Urmia during 20042005," Urmia Medical Journal, vol. 16, no. 4, pp. 212-217, 2004.

[5] K. Sharifi Sarasiabi, A. Madani, and S. Zare, "Prevalence of intestinal parasites in primary school publishes of Bandar Abbas," Journal of Hormozgan University of Medical Sciences, vol. 4, no. 5, pp. 25-30, 2002.

[6] B. Ezatpour, A. S. Chegeni, F. Abdollahpour, M. Aazami, and M. Alirezaei, "Prevalence of parasitic contamination of raw vegetables in Khorramabad, Iran," Food Control, vol. 34, no. 1, pp. 92-95, 2013.

[7] J. G. Damen, E. B. Banwat, D. Z. Egah, and J. A. Allanana, "Parasitic contamination of vegetables in Jos, Nigeria," Annals of African Medicine, vol. 6, no. 3, pp. 115-118, 2007.

[8] H. Soleimnanpoor, A. Zohor, and A. Ebrahimzadeh, "The survey of parasitic contamination of vegetables in Zabol city during 2011-2012," Zabol University of Medical Sciences, vol. 3, no. 2, pp. 40-47, 2013.

[9] A. S. Arani, R. Alaghehbandan, L. Akhlaghi, M. Shahi, and A. R. Lari, "Prevalence of intestinal parasites in a population in south of Tehran, Iran," Revista do Instituto de Medicina Tropical de Sao Paulo, vol. 50, no. 3, pp. 145-149, 2008.

[10] F. A. Dehghani and M. Azizi, "Study of the rate of contamination of intestinal parasites among workers in fast food outlets of Yazd," Journal of Shahid Sadoughi University of Medical Sciences and Health Services, vol. 11, no. 1, pp. 22-28, 2003.

[11] S. Salary and H. Safizadeh, "Prevalence of intestinal parasite infestation in the food suppliers of Kerman City, Iran, in 2010," Journal of Health \& Development, vol. 1, no. 4, pp. 315-322, 2013.
[12] T. Razavyoon and J. Massoud, "Intestinal parasitic infection in Feraydoon Kenar, Mazandaran," Journal of School of Public Health and Institute of Public Health Research, vol. 1, no. 1, pp. 39-49, 2003.

[13] M. Arbabi and S. A. Talari, "Intestinal parasites among students of Kashan University of Medical Sciences," Journal of Ilam University of Medical Sciences, vol. 12, no. 44-45, pp. 24-33, 2005.

[14] A. Daryani and G. H. Ettehad, "Prevalence of intestinal infestation among primary school students in Ardabil, 2003," Journal of Ardabil University of Medical Sciences, vol. 5, no. 3, pp. 229234, 2005.

[15] N. E. Atash, R. Ghorbani, S. Peyvandi, and S. Imani, "Prevalence of oxyuriasis and some related factors in kindergarten and primary school children in urban areas of Semnan province," Journal of Semnan University of Medical Sciences, vol. 9, no. 1, pp. 67-74, 2007.

[16] S. Ranjbar-Bahadori, A. Dastorian, and B. Heidari, "Prevalence of intestinal parasites in Ghaemshahr in 2004," Medical Science Journal of Islamic Azad Univesity-Tehran Medical Branch, vol. 15, no. 3, pp. 151-155, 2005.

[17] A. Siyadatpanah, F. Tabatabaei, A. E. Zeydi et al., "Parasitic contamination of raw vegetables in Amol, North of Iran," Archives of Clinical Infectious Diseases, vol. 8, no. 2, pp. 159-183, 2013.

[18] P. Ayeh-Kumi, S. Quarcoo, G. Kwakye-Nuako, J. Kretchy, A. Osafo-Kantanka, and S. Mortu, "Prevalence of intestinal parasitic infections among food vendors in Accra, Ghana," The Journal of Tropical Medicine and Parasitology, vol. 32, no. 1, pp. 1-8, 2009.

[19] M. Zarezadeh and M. Malakotian, "Prevalence of bacteria (Salmonella, Shigella) and intestinal parasites among food handlers in Kerman, Iran, in 1390," Pajoohandeh Journal, vol. 19, no. 1, pp. 55-59, 2014.

[20] Z. Aminzadeh, S. Afrasiabian, and L. Gachkar, "Intestinal parasitism in food-sellers in Sanandaj, 1997," Pejouhandeh, vol. 6, no. 5, pp. 449-452, 2002.

[21] Z. Aminzadeh, F. Shaker, M. Nazari, and L. Gachkar, "Prevalence of intestinal parasite in food handlers in Varamin 2002," Journal of Paramedical Sciences, vol. 1, no. 3, pp. 157-162, 2002.

[22] M. Fallah, S. Sadeghian, H. Taherkhani, F. Habibi, and Z. Heidar Barghi, "Study of parasitic and bacterial infections in the foodhandling personnel, Ramadan, Iran," Journal of Research in Health Sciences, vol. 4, no. 1, pp. 3-10, 2011.

[23] S. Rouhani, K. Reshad, and A. Athari, "Surveying the prevalence of intestinal parasites' infection in food handlers in Nowshahr and Chalous," Pajouhesh dar Pezeshki, vol. 24, no. 1, pp. 15-20, 2000.

[24] F. Koohsar, A. Amini, A. Ayatollahi, G. Noshak, H. HedayatMofidi, and M. Namjoo, "The prevalence of intestinal parasitic infections in food handlers inGorgan, Iran," Med Lab J, vol. 6, no. 1, pp. 26-34, 2012.

[25] G. Molavi, J. Masoud, I. Moubedi, and G. Hassanpour, "Prevalence of intestinal parasites in Esfahan municipal workers," Journal of School of Public Health and Institute of Public Health Research, vol. 5, no. 3, pp. 43-50, 2007.

[26] P. Kamau, P. Aloo-Obudho, E. Kabiru et al., "Prevalence of intestinal parasitic infections in certified food-handlers working in food establishments in the City of Nairobi, Kenya," Journal of Biomedical Research, vol. 26, no. 2, pp. 84-89, 2012.

[27] D. Zaglool, Y. Khodari, R. Othman, and M. Farooq, "Prevalence of intestinal parasites and bacteria among food handlers in a tertiary care hospital," Nigerian Medical Journal, vol. 52, no. 4, pp. 266-270, 2011. 
[28] M. A. Babiker, M. S. M. Ali, and E. S. Ahmed, "Frequency of intestinal parasites among food-handlers in Khartoum, Sudan," Eastern Mediterranean Health Journal, vol. 15, no. 5, pp. 10981104, 2009.

[29] F. Kheyrandish, E. Badparva, and M. Tarahi, "Prevalence of intestinal parasites in Khorramabad bakeries' workers in 2001," Yafteh, vol. 5, no. 17, pp. 45-50, 2004.

[30] F. Shidfar, M. Aghilinegad, and R. Nasrifar, "Intestinal Parasitological infection of employee in food manufacture anddistribution centers of Ilam University of Medical Sciences," Iran Occupational Health, vol. 2, no. 1, pp. 24-27, 2005.

[31] D. Balarak, Y. Mahdavi, M. J. Modrek, S. Sadeghi, and A. Ali Joghataei, "Prevalence of parasitic contamination of raw vegetables in Ahar, Iran," International Journal of Analytical, Pharmaceutical and Biomedical Sciences, vol. 5, no. 1, pp. 28-32, 2016.

[32] G. Andargie, A. Kassu, F. Moges, M. Tiruneh, and K. Huruy, "Prevalence of bacteria and intestinal parasites among foodhandlers in Gondar Town, Northwest Ethiopia," Journal of Health, Population and Nutrition, vol. 26, no. 4, pp. 451-455, 2008.

[33] S. Khurana, N. Taneja, R. Thapar, M. Sharma, and N. Malla, "Intestinal bacterial and parasitic infections among food handlers in a tertiary care hospital of North India," Tropical Gastroenterology, vol. 29, no. 4, pp. 207-209, 2008.

[34] B. Abera, F. Biadegelgen, and B. Bezabih, "Prevalence of Salmonella typhi and intestinal parasites among food handlers in Bahir Dar Town, Northwest Ethiopia," Ethiopian Journal of Health Development, vol. 24, no. 1, pp. 46-50, 2010.

[35] O. A. Morenikeji, N. C. Azubike, and A. O. Ige, "Prevalence of intestinal and vector-borne urinary parasites in communities in south-west Nigeria," Journal of Vector Borne Diseases, vol. 46, no. 2, pp. 164-167, 2009.

[36] D. G. Esparar, V. Y. Belizario, and J. Relos, "Prevalence of intestinal parasitic infections among food-handlers of a tertiary hospital in Manila using direct fecal smear andformalin ether concentration technique," The Philippine Journal of Microbiology and Infectious Diseases, vol. 33, no. 3, pp. 99-103, 2004.

[37] D. Balarak, M. Ebrahimi, M. J. Modrek, E. Bazrafshan, A. H. Mahvi, and Y. Mahdavi, "Investigation of parasitic contaminations of vegetables sold in markets in the city of Tabriz in 2014," Global Journal of Health Science, vol. 8, no. 10, pp. 178-184, 2016.

[38] M. M. Zain and N. N. Naing, "Sociodemographic characteristics of food handlers and their knowledge, attitude and practice towards food sanitation: a preliminary report," Southeast Asian Journal of Tropical Medicine and Public Health, vol. 33, no. 2, pp. 410-417, 2002.

[39] I. F. Angelillo, N. M. A. Viggiani, L. Rizzo, and A. Bianco, "Food handlers and foodborne diseases: knowledge, attitudes, and reported behavior in Italy," Journal of Food Protection, vol. 63 , no. 3, pp. 381-385, 2000. 

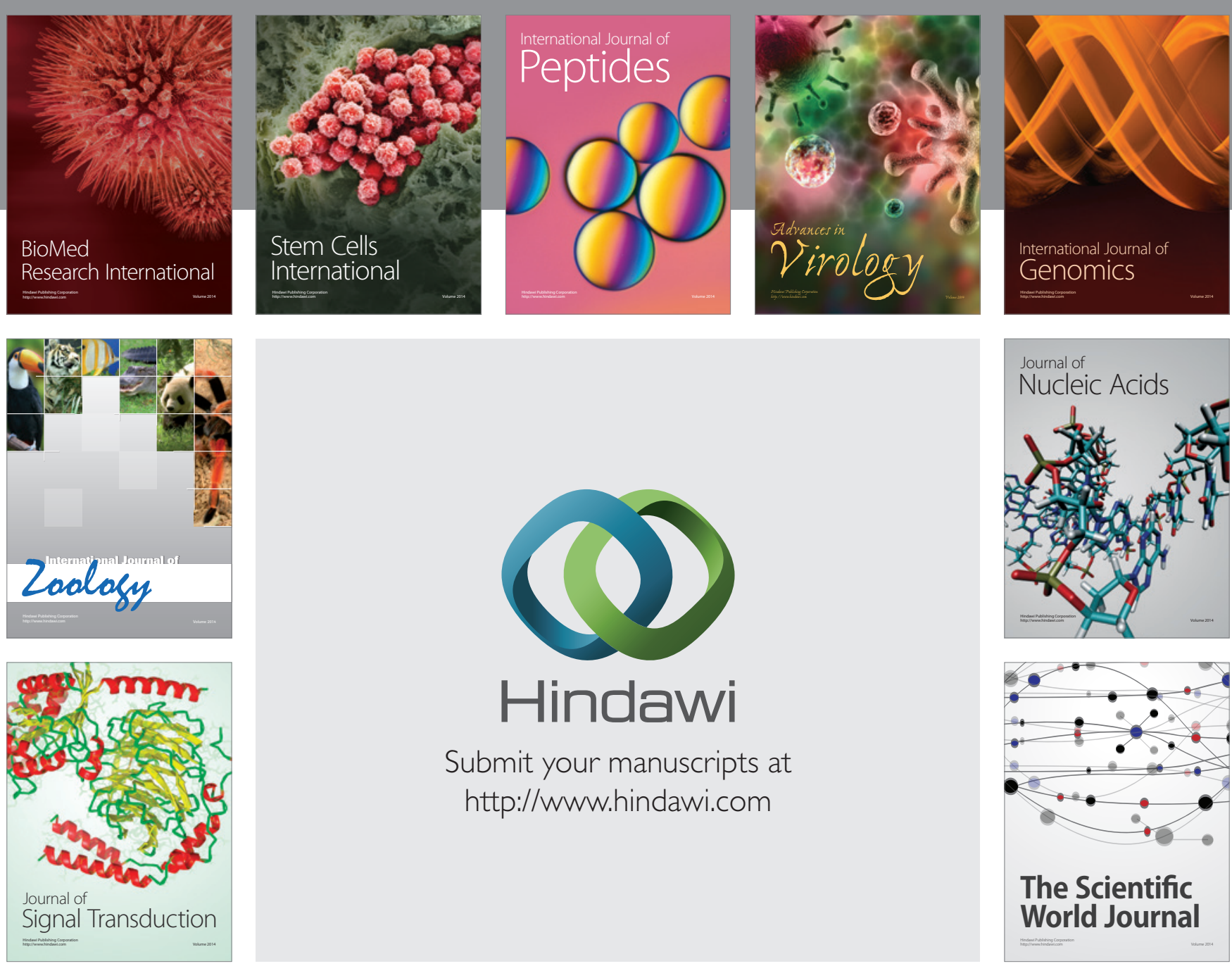

Submit your manuscripts at

http://www.hindawi.com
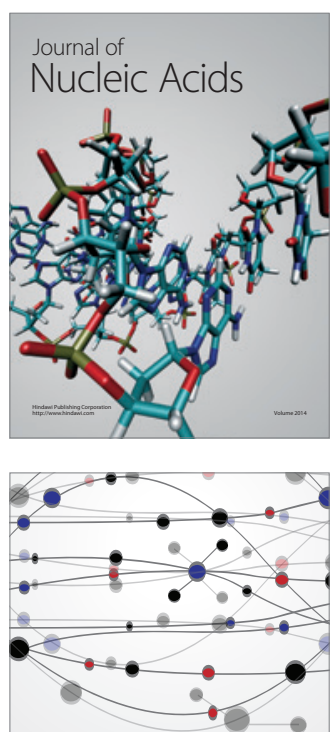

The Scientific World Journal
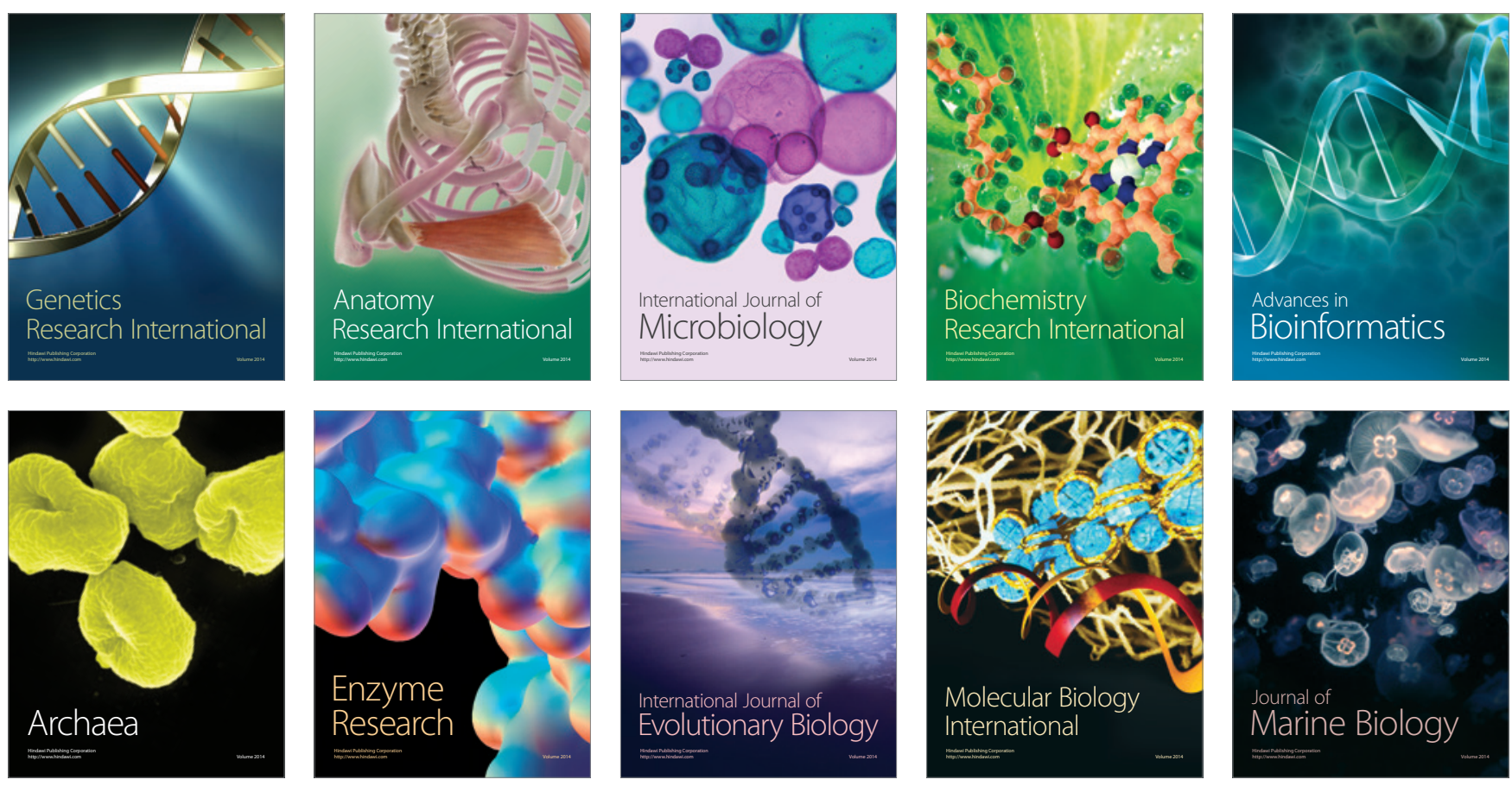